\title{
Loop Antenna Located on Magnetic Plate for RFID Tag
}

\author{
Mitsuo Taguchi ${ }^{(1)}$, Takashi Fukahori ${ }^{(2)}$, and Hideaki Shimoda ${ }^{(3)}$ \\ ${ }^{(1)}$ Dept. of Electrical \& Electronic Eng., Nagasaki University \\ (2), (3) Graduate School of Science and Technology, Nagasaki University \\ 1-14 Bunkyo-machi, Nagasaki-shi, 852-8521, Japan \\ E-mail: ${ }^{(1)}$ mtaguchi@nagasaki-u.ac.jp, ${ }^{(2)}$ d707194h@cc.nagasaki-u.ac.jp
}

\section{Introduction}

With the rapid development of RFID system, small tag antennas are desired [1]. By now, many techniques such as changing the current path, loading the matched circuit, and using dielectric and magnetic materials have been proposed to miniaturize antennas [2]. Magnetic materials are lossy at high frequencies. Recently, however, the low loss magnetic materials are developed for the application in the UHF frequencies [3].

In this paper, a rectangular loop antenna with a small loop located on the low loss magnetic plate for UHF RFID tag is numerically analyzed. In the numerical analysis, the electromagnetic simulator WIPL-D based on the Method of Moment is used [4].

\section{Antenna structure and analytical conditions}

Figure 1 shows the structure of the rectangular loop antenna located on the magnetic plate. A small loop is connected near the feed point of the rectangular loop for impedance adjustment. The thickness of antenna conductor is $0.1 \mathrm{~mm}$. The relative permittivity and permeability of the magnetic plate are 9.79 and 2.16 $-\mathrm{j} 0.05$, respectively.

In the numerical calculation by WIPL-D, the magnetic material is assumed to be isotropic. The design frequency is $950 \mathrm{MHz}$ and the calculation frequency is from $750 \mathrm{MHz}$ to $1.25 \mathrm{GHz}$.

\section{Numerical results}

The wavelength within the magnetic material with the relative permittivity $\varepsilon_{r}$ and permeability $\mu_{r}$ is expressed as follows.

$$
\lambda=\frac{\lambda_{0}}{\sqrt{\varepsilon_{r} \mu_{r}}}, \lambda_{0} \text { : wavelength in free space. }
$$

Therefore, the wavelength shortening rate depends on the product of the relative permittivity and permeability. Figure 2 shows the current distributions of the antenna in free space, located on a magnetic plate and a dielectric plate. The parameters of the antennas are $\mathrm{L}_{1}=\mathrm{L}_{2}=87 \mathrm{~mm}, \mathrm{w}_{1}=2 \mathrm{~mm}, \mathrm{~L}_{3}=\mathrm{L}_{4}=8 \mathrm{~mm}$, and $\mathrm{w}_{2}=2 \mathrm{~mm}$. The relative permittivity of the dielectric plate is $21.1-\mathrm{j} 0.488$. This 
value is equal to the product of the relative permittivity and permeability of the magnetic plate. It can be observed from Figure 2 the wavelength of the current on the antenna located on the magnetic plate is equal to that on the antenna located on the dielectric plate.

As the input impedance of the IC chip is $30-\mathrm{j} 108 \Omega$, the input impedance of the antenna should be adjusted to be $30+\mathrm{j} 108 \Omega$ at $950 \mathrm{MHz}$. Figure 3 shows the input impedance characteristics of the optimized antennas. The size of the magnetic plate is $\mathrm{L}_{5}=116 \mathrm{~mm}$ by $\mathrm{L}_{6}=40 \mathrm{~mm}$ by $\mathrm{t}_{\mathrm{m}}=2 \mathrm{~mm}$. The input impedances of both antennas are close to the $30+\mathrm{j} 108 \Omega$ around $950 \mathrm{MHz}$. Figure 4 shows the matching loss characteristics of these antennas. If the input impedance of the antenna is $Z_{A}=R_{A}+j X_{A}$ and that of the IC chip is $Z_{I C}=R_{I C}+j X_{I C}$, the matching loss is defined as follows [5]:

$$
M=\frac{\left(R_{A}+R_{I C}\right)^{2}+\left(X_{A}+X_{I C}\right)^{2}}{4 R_{A} R_{I C}} .
$$

The parameters of the antenna without the magnetic plate are $\mathrm{L}_{1}=100 \mathrm{~mm}, \mathrm{~L}_{2}=$ $70 \mathrm{~mm}, \mathrm{w}_{1}=2 \mathrm{~mm}, \mathrm{~L}_{3}=10 \mathrm{~mm}, \mathrm{~L}_{4}=9 \mathrm{~mm}$, and $\mathrm{w}_{2}=2 \mathrm{~mm}$. On the other hand, those of the antenna located on the magnetic plate are $\mathrm{L}_{1}=94 \mathrm{~mm}, \mathrm{~L}_{2}=18 \mathrm{~mm}$, $\mathrm{w}_{1}=2 \mathrm{~mm}, \mathrm{~L}_{3}=8.5 \mathrm{~mm}, \mathrm{~L}_{4}=8.5 \mathrm{~mm}, \mathrm{w}_{2}=2 \mathrm{~mm}$. The area of antenna is reduced by $76 \%$.

Figure 5 shows the electric field radiation patterns of these antennas. The radiation patterns of both antennas are almost the same.

\section{Conclusion}

A rectangular loop antenna with a small loop on the low loss magnetic plate for UHF RFID tag has been analyzed numerically. The antenna size has been miniaturized by $76 \%$ due to a magnetic plate. The radiation pattern of the miniaturized antenna is almost the same as that of the antenna without the magnetic plate. The experimental analysis of the proposed antenna will be left in the future.

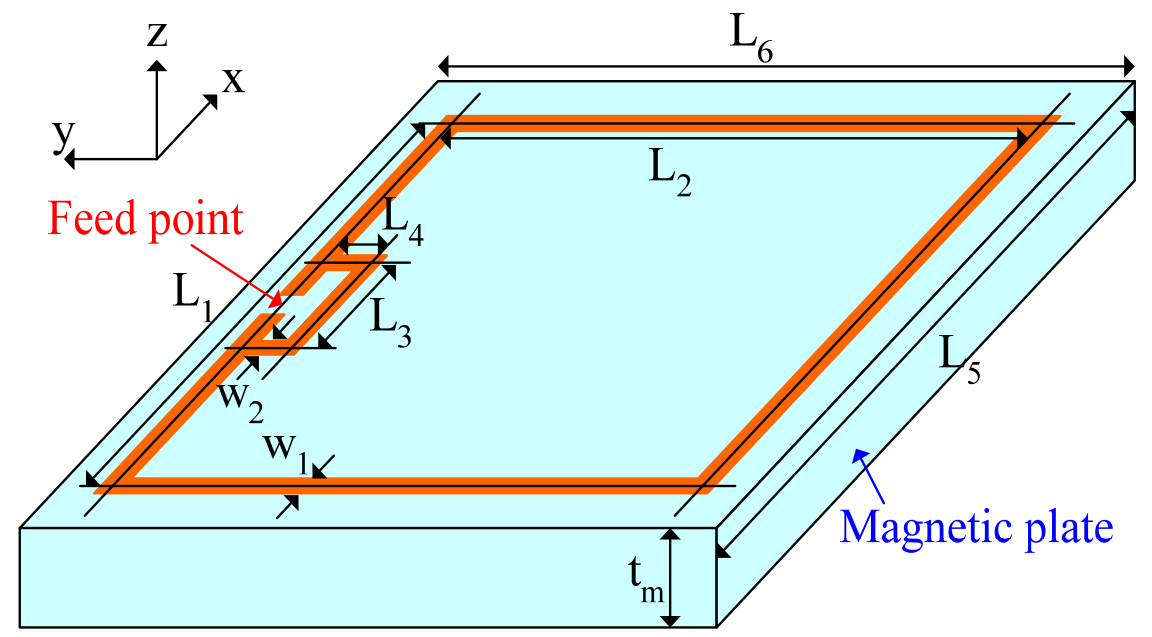

Fig. 1 Structure of antenna 


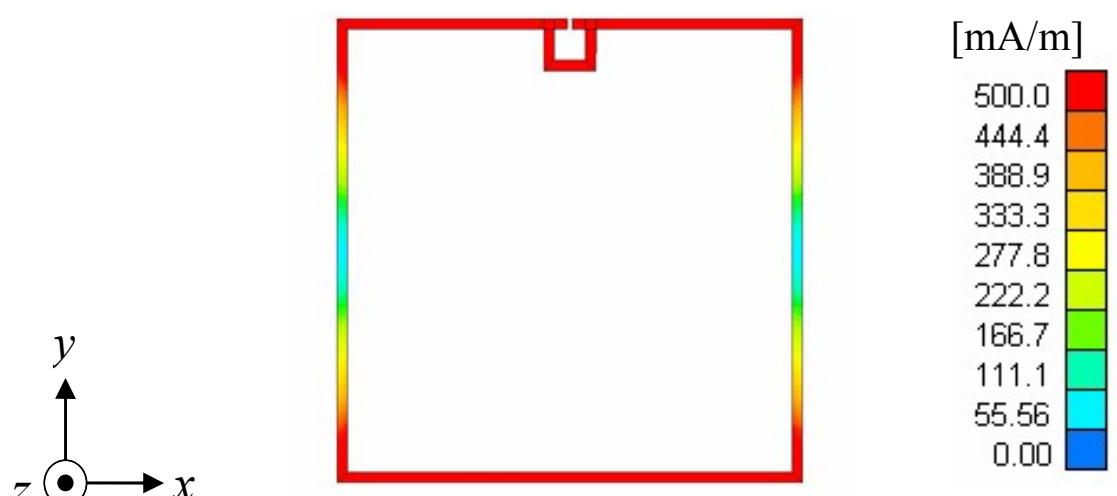

(a) In free space

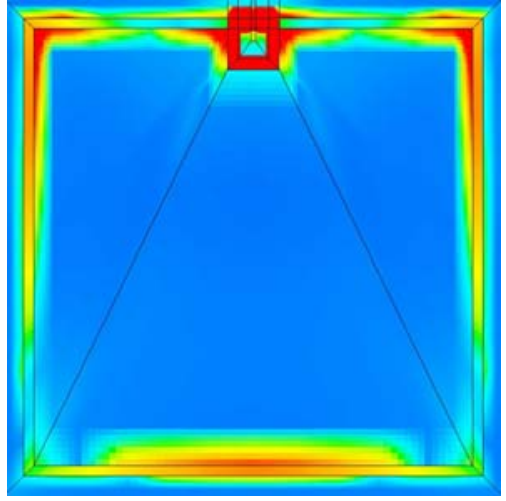

(b) With dielectric plate $\left(\varepsilon_{r}=21.1-\mathrm{j} 0.488\right)$



(c) With magnetic plate $\left(\varepsilon_{r}=9.79, \mu_{r}=2.16-\mathrm{j} 0.05\right)$

$\mathrm{L}_{1}=87 \mathrm{~mm}, \mathrm{~L}_{2}=87 \mathrm{~mm}, \mathrm{w}_{1}=2 \mathrm{~mm}, \mathrm{~L}_{3}=8 \mathrm{~mm}, \mathrm{~L}_{4}=8 \mathrm{~mm}$, $\mathrm{w}_{2}=2 \mathrm{~mm}, \mathrm{~L}_{5}=109 \mathrm{~mm}, \mathrm{~L}_{6}=109 \mathrm{~mm}, \mathrm{t}_{\mathrm{m}}=2.1 \mathrm{~mm}$

Fig. 2 Current distributions of loop antennas at $950 \mathrm{MHz}$

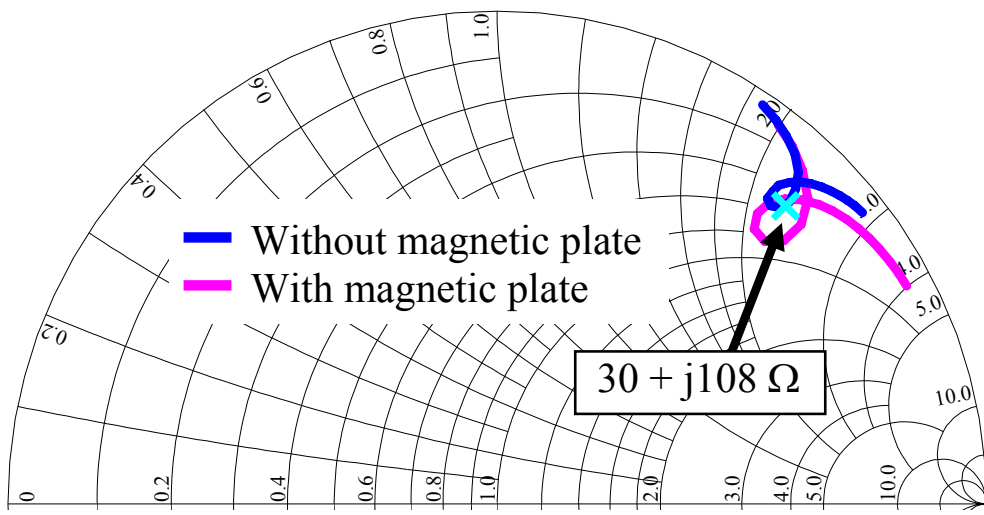

Without magnetic plate: $\mathrm{L}_{1}=100 \mathrm{~mm}, \mathrm{~L}_{2}=70 \mathrm{~mm}, \mathrm{w}_{1}=2 \mathrm{~mm}, \mathrm{~L}_{3}=10 \mathrm{~mm}$, $\mathrm{L}_{4}=9 \mathrm{~mm}, \mathrm{w}_{2}=2 \mathrm{~mm}$

With magnetic plate: $\mathrm{L}_{1}=94 \mathrm{~mm}, \mathrm{~L}_{2}=18 \mathrm{~mm}, \mathrm{w}_{1}=2 \mathrm{~mm}, \mathrm{~L}_{3}=8.5 \mathrm{~mm}$, $\mathrm{L}_{4}=8.5 \mathrm{~mm}, \mathrm{w}_{2}=2 \mathrm{~mm}$

Fig. 3 Input impedance characteristics of loop antennas 


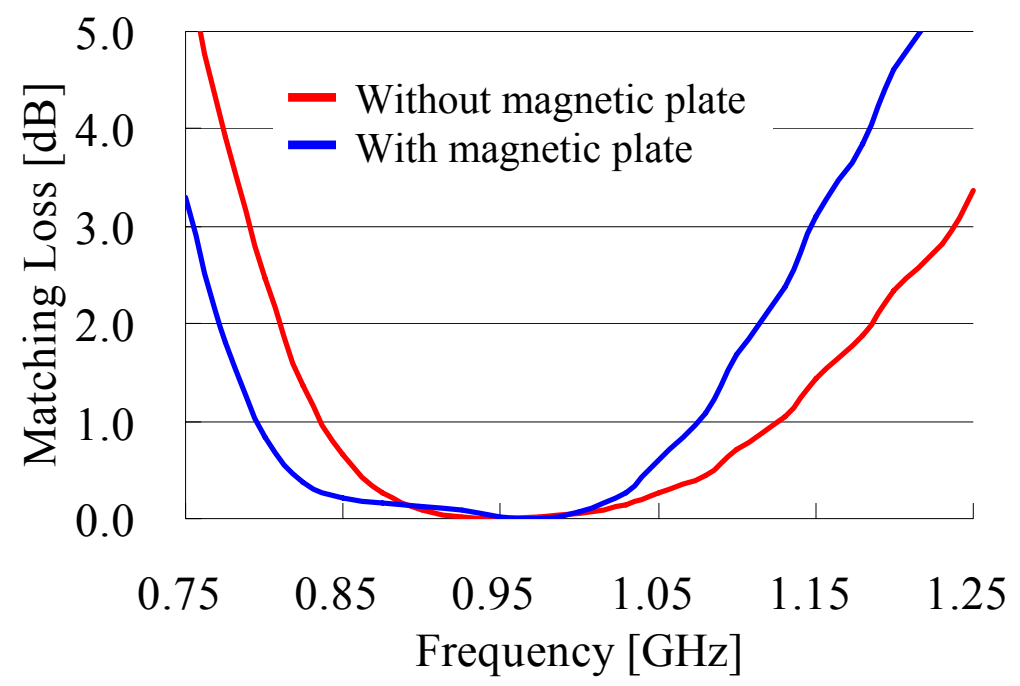

Fig. 4 Matching loss characteristics of loop antennas

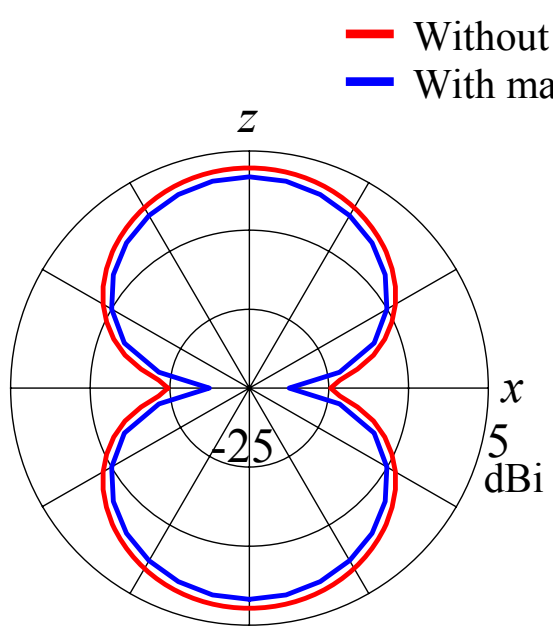

(a) xz-plane

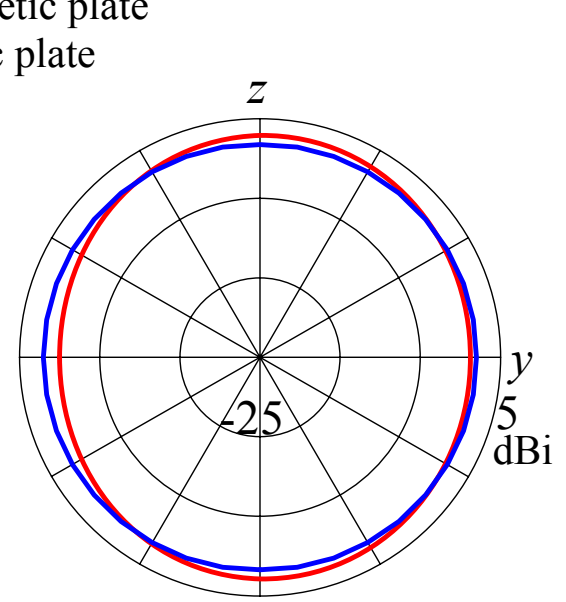

(b) yz-plane

Fig. 5 Electric field radiation patterns of loop antennas at $950 \mathrm{MHz}$

\section{References}

[1] K. Finkenzeller: "RFID handbook", John Wiley \& Sons, 2003.

[2] H. Arai: "Small antennas: Downsizing techniques and its index factor", IEICE Trans. on Communications, vol. J87-B, no. 9, pp. 1140-1148, Sept. 2004 (in Japanese).

[3] N. Kitahara, T. Mizumoto: "Magnetic ceramics materials with high permittivity and low loss", IEICE Trans. on Communications, vol. J86-C, no. 4, pp. 450-456, April 2003 (in Japanese).

[4] http://www.wipl-d.com/

[5] K. Hayama, K. Saito: "Design technique of 1 inch square UHF RFID tag antenna for product", Omron Technics, Vol. 46, No. 2, 2006 (in Japanese). 